\title{
LETTER
}

\section{Health Literacy and Discharge Instruction Adherence}

\author{
Niccolò Giaj Levra, $\mathrm{MD}^{7}$, Francesco Andrea Cuniberti ${ }^{7}$, Alessandro Rava ${ }^{7}$, Giulia Vietti, $\mathrm{MD}^{7}$, and \\ Savino Sciascia, $M^{1,2}$ \\ 'Università di Torino, Turin, Italy; ${ }^{2}$ Centro di Ricerche di Immunopatologia e Documentazione su Malattie Rare (CMID), Struttura Complessa a \\ Direzione Universitaria di Immunologia Clinica Ospedale Torino Nord Emergenza San G. Bosco, Torino, Italy.
}

$\mathrm{J}$ Gen Intern Med 27(3):273

DOI: $10.1007 / \mathrm{s} 11606-011-1969-1$

(c) Society of General Internal Medicine 2012

$\mathrm{T}$ o The Editor-Despite economic and social growth, low literacy continues to be a significant issue across the developed world. The 1996 OECD International Adult Literacy Survey found $22 \%$ of US adults and $23 \%$ of UK adults to be performing at the lowest level of a 5-point scale of functional literacy. ${ }^{1,2}$ We would like to join the emerging debate recently arising from the Journal of General Internal Medicine $^{3}$ about this topic, giving our personal point of view, as medical or health-related sciences students. As medical and pharmacy students, we feel that the schools of medicine and health-related sciences must redouble their efforts to improve life sciences instruction in order to create true caregivers able to serve as a resource through engagement in health and science promotion. Individuals who are not able to understand the nature of their illnesses may make bad judgments about them. Thus, it is desirable that schools of medicine and health-related sciences address the apparent missing links between biological literacy and evidence-based medicine in medical education program design and curricula development. This will allow medical and health-related sciences students to begin their lifelong journey towards the development of medical culture focusing on science and health promotion and disease prevention.

Corresponding Author: Savino Sciascia, MD; Centro di Ricerche di Immunopatologia e Documentazione su Malattie Rare (CMID), Struttura Complessa a Direzione Universitaria di Immunologia Clinica Ospedale Torino Nord Emergenza San G. Bosco, Torino, Italy (e-mail: savino.sciascia@unito.it).

\section{REFERENCES}

1. Easton P, Entwistle VA, Williams B. Health in the 'hidden population' of people with low literacy. A systematic review of the literature. BMC Public Health. 2010;10:459.

2. Moser CS. Improving literacy and numeracy: a fresh start. London: DfEE Publications; 1999.

3. Lindquist LA, Go L, Fleisher J, Jain N, Friesema E, Baker DW. Relationship of Health Literacy to Intentional and Unintentional NonAdherence of Hospital Discharge Medications. J Gen Intern Med. 2011 Online: Oct 5, 2011. 